\title{
Access to hip and knee replacement surgery in patients with chronic diseases according to patient-reported pain and functional status
}

Bélène Podmore ${ }^{1,2^{*}}$ D, Andrew Hutchings ${ }^{1,2}$, Sujith Konan ${ }^{3}$, John Robson ${ }^{4}$ and Jan van der Meulen ${ }^{1,2}$

\begin{abstract}
Background: An increasing number of patients undergoing hip or knee replacement have chronic diseases. It has been suggested that the presence of chronic diseases may affect access to this type of surgery in the English National Health Service (NHS). We examined the access to hip and knee replacement surgery in patients with and without chronic diseases according to preoperative patient-reported pain, functional status and symptom duration.

Methods: We analysed data of 640,832 patients who had hip or knee surgery between 2009 and 2016 in England. Multivariable regression was used to estimate the impact of 11 chronic diseases on severity of joint problems as measured on a scale from 0 to 48 by Oxford Hip (OHS) and Knee Scores (OKS) just before surgery and on likelihood of long-standing joint problems (> 5 years pre-operatively).

Results: Patients with chronic diseases reported more severe joint problems than patients without (OHS differences ranged from $1.1[95 \% \mathrm{Cl} 0.93,1.2]$ to $2.5[95 \% \mathrm{Cl} 2.3,2.7]$ and OKS differences from $0.5[95 \% \mathrm{Cl} 0.3,0.7]$ to $2.6[95 \%$ $\mathrm{Cl} 2.4,2.7]$ for the 11 chronic diseases) but the differences remain small. When analysed separately, patients with chronic diseases reported both more severe pain and poorer functional status. Six chronic diseases in hip patients and two in knee patients increased the likelihood that they had long-standing joint problems. The severity of joint problems just before surgery increased with the number of chronic diseases (OHS differences; one chronic disease $(1.5[95 \% \mathrm{Cl} 1.4,1.5])$ to four or more $(5.8[95 \% \mathrm{Cl} 5.6,6.0]))$.
\end{abstract}

Conclusions: Patients with chronic diseases reported more severe joint problems immediately before hip or knee replacement surgery suggesting they have hip or knee replacement later in the course of their joint disease.

Keywords: Healthcare disparities, Access to surgery, Chronic disease, Surgical procedure

\footnotetext{
* Correspondence: belene.podmore@lshtm.ac.uk

'Department of Health Services Research \& Policy, London School of Hygiene \& Tropical Medicine, 15-17 Tavistock Place, London WC1H 9SH, UK

${ }^{2}$ Clinical Effectiveness Unit, The Royal College of Surgeons of England, London, UK

Full list of author information is available at the end of the article
}

(c) The Author(s). 2020 Open Access This article is licensed under a Creative Commons Attribution 4.0 International License, which permits use, sharing, adaptation, distribution and reproduction in any medium or format, as long as you give appropriate credit to the original author(s) and the source, provide a link to the Creative Commons licence, and indicate if changes were made. The images or other third party material in this article are included in the article's Creative Commons licence, unless indicated otherwise in a credit line to the material. If material is not included in the article's Creative Commons licence and your intended use is not permitted by statutory regulation or exceeds the permitted use, you will need to obtain permission directly from the copyright holder. To view a copy of this licence, visit http://creativecommons.org/licenses/by/4.0/ The Creative Commons Public Domain Dedication waiver (http://creativecommons.org/publicdomain/zero/1.0/) applies to the data made available in this article, unless otherwise stated in a credit line to the data. 


\section{Background}

Hip and knee replacement surgery is one of the most common and effective surgical treatments leading to significant improvements in quality of life [1]. Despite this in publicly funded healthcare systems such as England [2], Canada [3], and New Zealand [4] eligibility criteria restricting access to hip and knee replacement surgery, have recently been introduced to limit inappropriate use of joint replacement surgery and reduce healthcare cost. Eligibility criteria in England have included the severity of preoperative functional status [5] and pain [2], the requirement that a patient's body mass index is lower than $30 \mathrm{~kg} / \mathrm{m}^{2}$, and the optimisation of pre-existing chronic diseases [6-8]. There is no evidence, however, to suggest that limiting access according to any of these criteria is justified and these policies are not supported by clinical guidelines issued by the National Institute for Health and Care Excellence (NICE) [9]. Furthermore, in a comprehensive systematic review of 70 studies, on outcomes of joint replacement surgery comparing patients with and without chronic diseases, the evidence does not suggest patients with chronic diseases benefit less from hip and knee replacement surgery [10].

In a recent qualitative study, we explored the views of healthcare professionals in the English NHS about referring and selecting patients with chronic diseases for joint replacement surgery [11]. These professionals reported that some patients with chronic diseases are not 'prepared' for surgery because their chronic diseases are not adequately controlled. As a result, these patients are often sent back to their general practitioner in primary care, fragmenting and delaying the surgical management of their joint problems, in some cases preventing surgery altogether [12]. In addition, such delays could lead to increased functional deterioration and pain of the osteoarthritic hip and knees and thereby also increased costs. Advanced osteoarthritis of the hip and knee is associated with increased health service use and opioid use [13, 14].

Previous research investigating variation in access to joint replacement surgery has used two different approaches. Some papers have measured access indirectly from a population perspective by focusing on those not receiving surgery and seeking to measure unmet need [15]. Others have looked at those who did receive surgery, studying variation in utilisation of surgery according to factors such as geographical area [16] or socioeconomic status [17]. The Patient Reported Outcome Measures (PROMs) programme that is being carried out in the English National Health Service (NHS) has provided a new opportunity to explore access as it provides information on the severity and the duration of the joint problems just before surgery in a nationally representative sample [17]. If there were differences in access, we might expect to see differences in the severity of joint problems and in their duration according to the presence of chronic disease. A similar approach has been used previously to look at the impact of socioeconomic status $[17,18]$.

In this paper, we therefore examined associations of the severity of joint problems (overall and separately in terms of pain and functional status) and the duration of the joint problems in patients with different chronic diseases just before hip or knee replacement surgery to get a better understanding of the impact that chronic diseases have on access to joint replacement surgery.

\section{Methods \\ Data sources}

We used data from the English national PROMs programme for elective hip and knee replacement surgery [19]. All NHS providers are required to participate and patients are asked to report their joint problems and wellbeing at the preoperative assessment clinic or on admission to hospital and then again 6 months after surgery. Over $75 \%$ of eligible patients complete the preoperative questionnaire [20]. The PROMs data were linked at patient level to data from the Hospital Episode Statistics (HES) database. HES contains administrative records of all admissions to all NHS hospitals in England. Eligibility was restricted to the first primary replacement surgery (Fig. 1).

\section{Defining chronic diseases}

The 11 chronic diseases that were included in the analysis were defined using ICD-10 codes in the linked hospital admissions HES data up to 1 year prior to the surgery. The 11 chronic diseases comprised heart disease, high blood pressure, problems caused by a stroke, leg pain when walking due to poor circulation, lung disease, diabetes, kidney disease, nervous system disease, liver disease, cancer, and depression. These chronic disease categories, used in the PROMs questionnaire and based on the work of Bayliss et al. [21], were selected because it allowed using a combination of already existing ICD-10 diagnosis-based comorbidity indices (Elixhauser, Royal College of Surgeons Charlson and Quan Charlson Comorbidity Index).

\section{Measures}

We used the Oxford Hip (OHS) and Knee Scores (OKS) as our measures of severity of joint problems just before surgery. These are derived from patient responses to 12 questions about pain and limits on physical functioning caused by the hip or the knee. Responses to each question are measured on a 5point scale. Response values are added up to produce an overall scale from 0 (worst) to 48 (best). The OKS and OHS have been validated and found to correlate with surgeon assessment of symptoms [22]. 


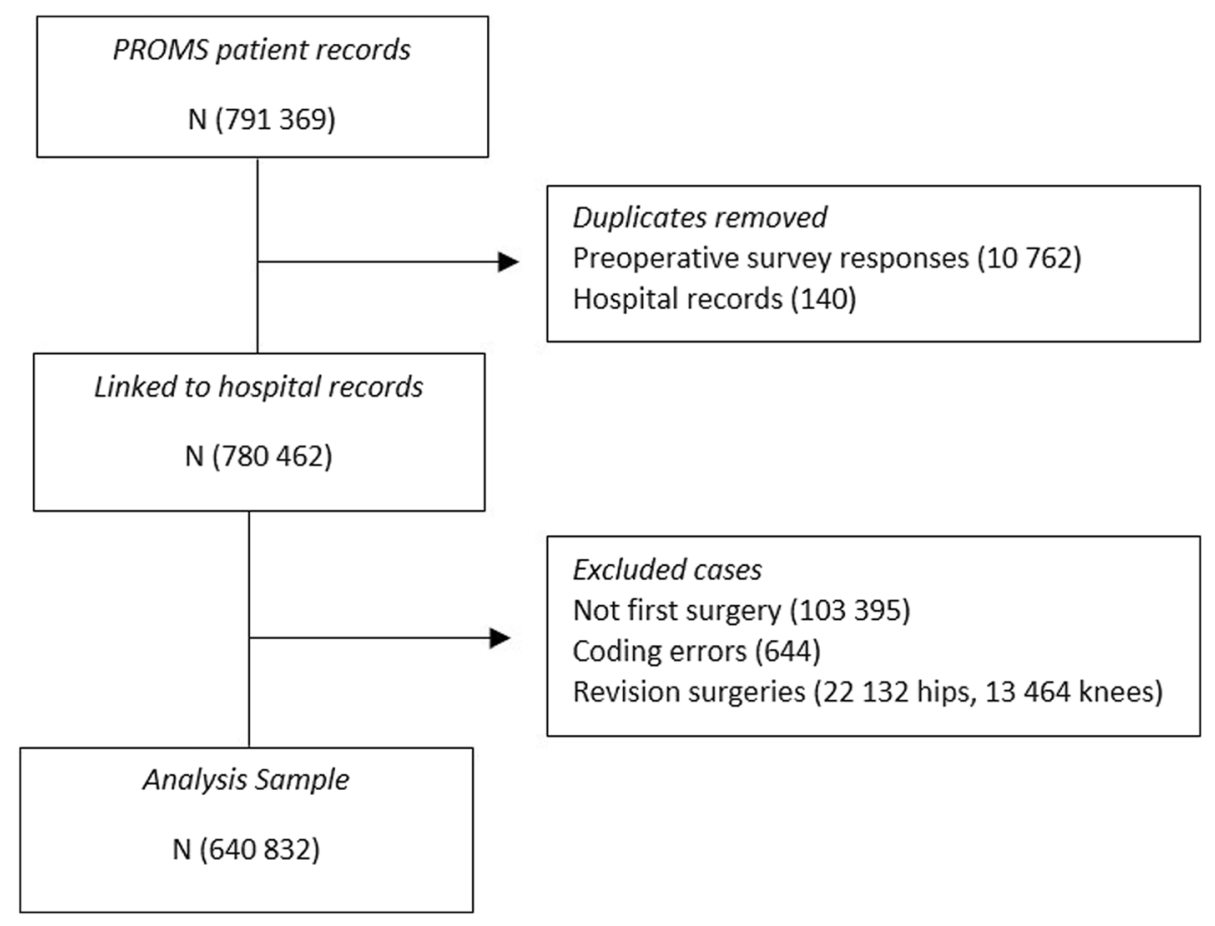

Fig. 1 Data Flow Chart

We also considered the questions related to pain and those related to functional status in the OHS and OKS separately. The severity of joint problems is typically measured using disease-specific measures such as the OKS and OHS. The challenge of using these measures, which are designed to assess only the severity of the hip or knee problem, is that they may also be influenced by chronic diseases [23, 24]. To explore this further, we looked separately at the scores for pain (for example, night pain and sudden pain) and for functional status (for example, ability to go shopping on your own and climb a flight of stairs). We hypothesised that pain is more 'joint-specific' than functional status and that it is therefore less likely to be influenced by chronic diseases. This approach has been used before to study the impact of pain and of functional status on patient satisfaction after hip and knee replacement surgery [25]. For the OKS, scores for the five questions on pain were added together as were those for the seven on functional status (see supplementary material). For the OHS, there were six questions each on pain and functional status.

A categorical measure of duration of joint problems was derived from responses to a single question asking patients how long they had experienced problems with their hip or the knee on which they were about to have surgery. The four response categories included 'Less than 1 year', ' $1-5$ years', ' $6-10$ years', and 'More than 10 years'. We defined long-standing hip or knee problems as problems with a duration of joint problems of more than 5 years pre-operatively.

\section{Statistical analysis}

We estimated adjusted differences in mean preoperative pain and functional status using multivariable linear regression and calculated the mean scores according to the presence or absence of each chronic disease. We also estimated odds ratios (ORs) for having long-standing hip or knee problems for each chronic disease using multivariable logistic regression. The impact of the number of chronic diseases $(1,2,3$, or $\geq 4)$ on the severity of joint problems and duration of joint problems was also investigated to explore the effect of having multiple chronic diseases.

We adjusted for sociodemographic factors including age, sex, ethnicity and socioeconomic status (Index of Multiple Deprivation [26]) and other chronic diseases. Hospitals were added as a random effect. Missing values for ethnicity, age, sex and socioeconomic status were imputed with chained equations. Analyses were run on each of 10 imputed data sets and estimated parameters were combined using Rubin's rules [27]. Statistical results are presented with $95 \%$ confidence intervals and $p$ values. All statistical analysis were carried out using STATA V.15. 


\section{Results}

\section{Patient characteristics}

Six hundred forty thousand eight hundred thirty-two patients were eligible (Table 1). Their mean age was 68 and $41.8 \%$ were male. About $3 \%$ of patients reported a minority ethnic background with Black or Black British being the largest group but there was a high percentage of missing data. The most common chronic diseases were high blood pressure (52.8\%), heart disease (17.8\%), and lung disease (14.5\%). The least common chronic disease was liver disease (0.60\%). $35.3 \%$ of patients had one chronic disease and $32.3 \%$ two or more.

\section{Severity of joint problems}

Patients with any of the 11 chronic diseases for both hip and knee replacement surgery reported more severe joint problems than patients without chronic diseases just before surgery (Table 2). For hip replacement surgery, adjusted differences in severity of joint problems ranged from 1.06 (95\% CI 0.93, 1.19) for kidney disease to $2.49(95 \%$ CI $2.31,2.66)$ for diseases of the nervous system. For knee replacement surgery, adjusted differences in severity of joint problems ranged from 0.46 (95\% CI $0.26,0.66)$ for cancer patients to 2.58 (95\% CI $2.42,2.73)$ for patients with diseases of the nervous system. The largest differences in severity of joint problems for both hip and knee replacement were reported by patients with diseases of the nervous system, depression and liver disease and the smallest differences for high blood pressure, cancer and kidney disease.

When looking at pain and functional status scores separately, we found that patients with chronic diseases reported not only worse functional status but also more pain just before surgery than patients without chronic diseases for each of the 11 chronic diseases (Table 2). Similar to the overall OHS and OKS score, the stronger impact on both pain and functional status scores was found in patients with diseases of the nervous system and depression and the lowest in patients with kidney disease and cancer.

\section{Long-standing joint problems}

$18.5 \%$ of patients who had hip replacements reported long-standing joint problems (> 5 years) and $43.1 \%$ of those who had knee replacements. The impact of different chronic diseases on the likelihood that patients reported long-standing hip or knee problems showed a mixed picture (Fig. 2). For hip replacement surgery, six chronic diseases increased the likelihood that patients reported long-standing problems whereas three others reduced it. For knee replacement, the likelihood that patient reported long-standing problems was increased by two chronic diseases and decreased by two others.
Table 1 Population characteristics

\begin{tabular}{|c|c|c|}
\hline Characteristic & $\begin{array}{l}\text { Hip } \\
\text { replacement }\end{array}$ & $\begin{array}{l}\text { Knee } \\
\text { replacement }\end{array}$ \\
\hline No. of patient & $312,079(48.7)$ & $328,753(51.3)$ \\
\hline Mean (SD) OHS or OKS & $17.4(8.25)$ & $18.3(7.87)$ \\
\hline Mean (SD) EQ-5D & $0.33(0.33)$ & $0.39(0.32)$ \\
\hline Long-standing problems, n (\%) & $57,827(18.5)$ & $141,559(43.1)$ \\
\hline Age, mean (range) & $68(18-105)$ & $69(18-102)$ \\
\hline \multicolumn{3}{|l|}{ Gender, n (\%) } \\
\hline Male & $126,925(40.7)$ & $140,971(42.9)$ \\
\hline Female & $184,982(59.3)$ & $187,525(57.0)$ \\
\hline Missing, not stated & 172 & 257 \\
\hline \multicolumn{3}{|c|}{ Socioeconomic status by quintile group, $\mathrm{n}(\%)$} \\
\hline 1 (least deprived) & $74,380(23.4)$ & $69,582(21.2)$ \\
\hline 2 & $76,164(24.4)$ & $74,799(22.8)$ \\
\hline 3 & $55,793(17.9)$ & $62,851(19.1)$ \\
\hline 4 & $52,194(16.7)$ & $60,177(18.3)$ \\
\hline 5 (most deprived) & $50,408(16.2)$ & $58,327(17.7)$ \\
\hline Missing & 3140 & 3017 \\
\hline \multicolumn{3}{|l|}{ Ethnicity, n (\%) } \\
\hline White or White British & $271,959(98.3)$ & $279,159(94.5)$ \\
\hline Mixed background & $546(0.19)$ & $836(0.28)$ \\
\hline Asian or Asian British & $1239(0.45)$ & $10,445(3.53)$ \\
\hline Black or Black British & $1703(0.62)$ & $3347(1.13)$ \\
\hline Chinese or other ethnic & $1150(0.42)$ & $1706(0.58)$ \\
\hline Missing & 35,482 & 33,260 \\
\hline \multicolumn{3}{|l|}{ Chronic disease, n (\%) } \\
\hline Heart disease & $53,277(17.1)$ & $60,755(18.5)$ \\
\hline High Blood pressure & $151,163(48.4)$ & $187,815(57.1)$ \\
\hline Stroke & $3227(1.03)$ & $3530(1.07)$ \\
\hline $\begin{array}{l}\text { Leg pain due to poor } \\
\text { circulation }\end{array}$ & $5140(1.65)$ & $4955(1.51)$ \\
\hline Lung Disease & $43,481(13.9)$ & $51,176(15.6)$ \\
\hline Diabetes & $29,535(9.46)$ & $44,813(13.6)$ \\
\hline Kidney Disease & $16,428(5.26)$ & $18,000(5.48)$ \\
\hline Diseases of the Nervous System & $8483(2.72)$ & $9741(2.96)$ \\
\hline Liver Disease & $1888(0.60)$ & $1931(0.59)$ \\
\hline Cancer & $6354(2.04)$ & $5545(1.69)$ \\
\hline Depression & $13,367(4.28)$ & $14,814(4.51)$ \\
\hline \multicolumn{3}{|l|}{ Count of chronic diseases, n (\%) } \\
\hline 0 & $113,479(36.4)$ & $94,290(28.7)$ \\
\hline 1 & $107,139(34.3)$ & $119,012(36.2)$ \\
\hline 2 & $59,976(19.2)$ & $75,202(22.9)$ \\
\hline 3 & $22,929(7.35)$ & $29,761(9.05)$ \\
\hline $4+$ & 8556 (2.74) & 10,488 (3.19) \\
\hline
\end{tabular}




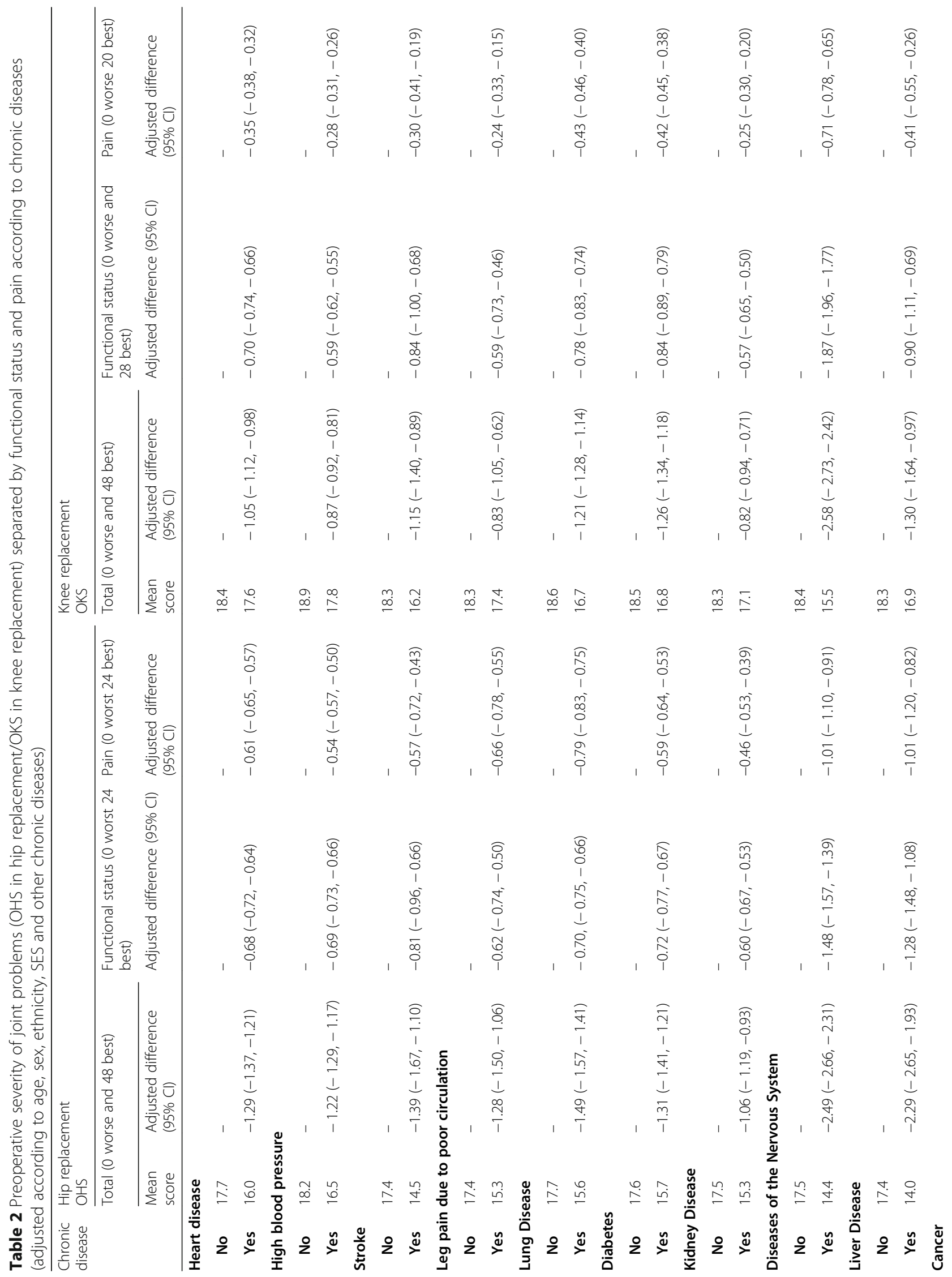




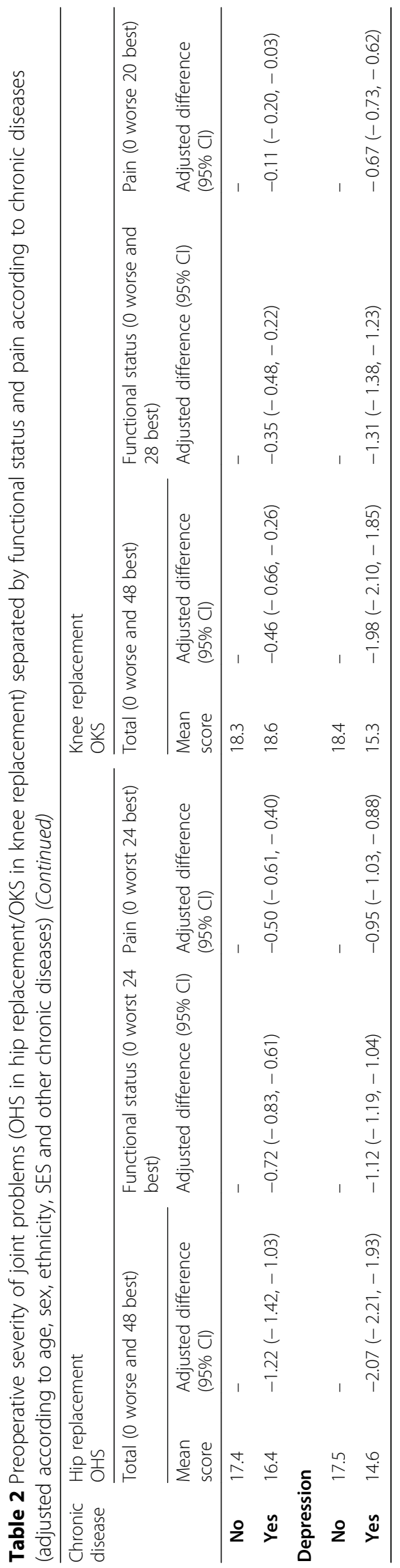




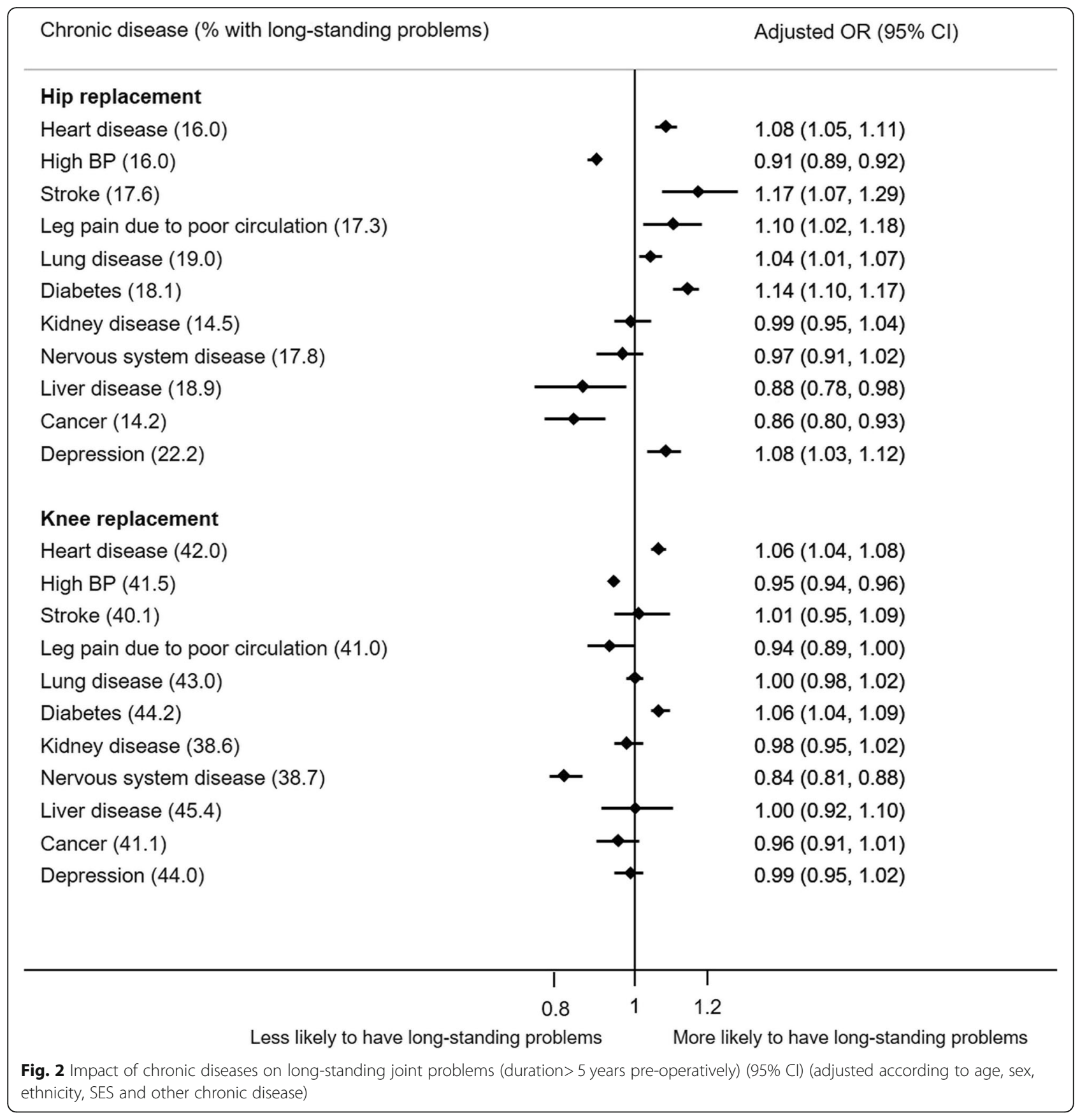

\section{Multiple chronic diseases}

The severity of joint problems just before surgery increased with the number of chronic diseases (Table 3). Compared with patients without chronic diseases who had a hip replacement, the adjusted differences in OHS increased from 1.45 (95\% CI 1.38, 1.52) for patients with one chronic disease to 2.79 (95\% CI 2.70, 2.87) for patients with two chronic diseases. The adjusted differences were largest for patients with four or more chronic diseases $(5.79,95 \%$ CI 5.61, 5.96). Compared with patients without chronic diseases who had a knee replacement, the adjusted differences increased from $1.06(95 \%$ CI $0.99,1.12)$ for patients with one chronic disease to 4.79 (95\% CI 4.64, 4.94) for patients with four or more chronic diseases. We observed a similar gradient both in hip and in knee replacement surgery patients when looking at pain and functional status separately. In patients with four chronic diseases, irrespective of whether they had a hip or a knee replacement, the most common combination was high blood pressure, heart disease, diabetes, and lung disease. 


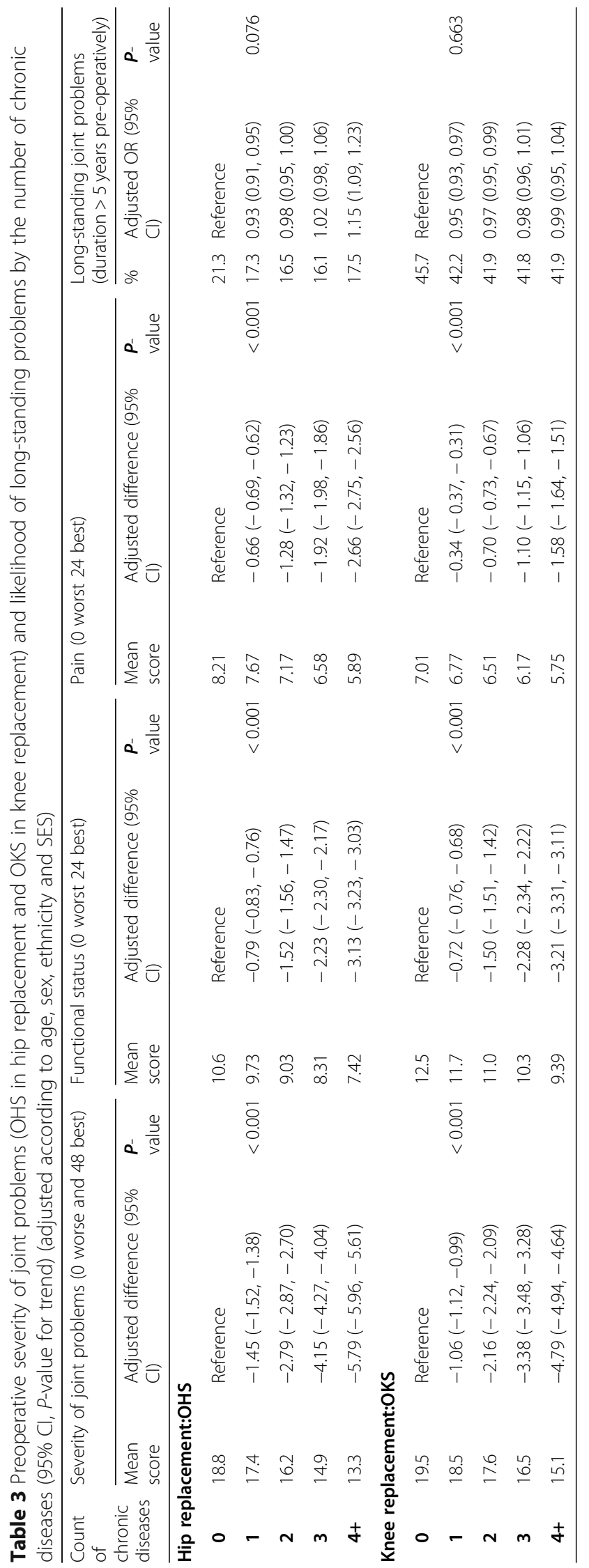


The impact of the number of chronic diseases on the likelihood of reporting long-standing joint problems was inconsistent. In hip patients, only patients with four or more chronic diseases were more likely to report longstanding problems (OR 1.15, 95\% CI 1.09, 1.23). In knee patients, an increasing number of chronic diseases had no impact on the likelihood of patients reporting longstanding problems.

\section{Discussion}

This study demonstrates that compared to patients without chronic diseases, patients with chronic diseases, especially those with liver disease, depression, and diseases of the nervous system, reported more severe joint problems immediately before undergoing a hip or knee replacement. Patients with chronic diseases reported not only worse functional status but also more pain just before surgery which suggests that patients with chronic diseases have truly worse joint problems regardless of any direct impact of chronic diseases on the diseasespecific measure. When looking at the number of chronic diseases, the severity of the joint problems increased with the number of chronic diseases. Patients with chronic diseases however reported little to no difference in duration of their joint problems compared to patients without chronic diseases although the difference was larger in patients undergoing hip replacement compared to patients undergoing knee replacement.

The observed differences in severity of joint problems were small but statistically significant for all of the 11 different chronic diseases. To interpret the size of the difference, they can be compared with defined 'minimally important differences' (MID), the smallest important differences in scores that patients report as beneficial. Suggested MID values are five points for both the OHS and OKS [28]. Only hip and knee patients with four or more chronic diseases reported differences in OHS and OKS scores more than five points larger than patients without chronic diseases.

Our findings about the duration of joint problems were not in alignment with the findings related to the severity of joint problems just before surgery. These inconsistent results may be due to recall bias, because patients may find it difficult to remember the actual onset of their hip or knee problems. Patients were asked, 'How long they had experienced problems with the hip or the knee on which they were about to have surgery?' In response to this question, patients may have reported the duration of problems of their most recent episode with a specific level of severity rather than their overall duration [29]. Previous studies have reported that this may be due to the lack of clarity of the question that was used to elicit information about symptom duration [29]. Nevertheless, increasing symptom duration has recently been reported to be a significant predictor of poorer outcome after surgery [30].

This study is the first to examine the relationship between chronic diseases and patient-reported pain, functional status and duration of joint problems immediately before surgery in a large representative sample of patients. One possible interpretation of our findings is that the severity of joint problems at the time of surgery represents delays in access to surgery, although our findings do not give an indication about the length of these delays. It can also be argued that our observation that patients with chronic disease report more severe joint problems than patients without may also be explained by information bias (e.g. patients with more severe joint problems are more likely to have other comorbidities recorded) or that pre-operative conservative treatment may be more effective in patients without than in patients with comorbidities.

We acknowledge that our finding of an association between the presence of chronic conditions and more severe joint problems does not prove a causal relationship. However, our interpretation is supported by the findings from our previous qualitative study which explored the views of healthcare professionals on the referral and selection of patients with chronic diseases for hip or knee replacement surgery in the English NHS [11]. This study showed that chronic diseases may create subtle barriers, for example when patients who are considered to be unprepared for surgery are referred back to their general practitioner in primary care.

Furthermore, delays in access in patients with chronic conditions may be linked to patients' reluctance to undergo surgery [31] or to clinicians' uncertainty about the indications for replacement surgery [32-34]. In previous studies with different groups of healthcare professionals, the presence of chronic diseases was found reported to be a reason that surgery should not be recommended because of the increased risks of surgery [35]. This is also one of the arguments to justify the restricted eligibility criteria for hip and knee replacement imposed by some regional commissioners of healthcare in England who require that chronic diseases are optimised before surgery [6-8].

Delays to surgery have also been linked to patient health-seeking behaviour and reluctance to undergo surgery [36]. Firstly, differences in thresholds for pain may explain variation in seeking clinical advice or having surgery. There is evidence that people from more socioeconomically deprived backgrounds - who are also more likely to have chronic diseases [37] - tend to accept a higher threshold of chronic pain and functional limitation before having surgery [38]. Secondly, a number of studies have reported differences in patient preferences and expectations for joint replacement surgery. For 
example, it was shown that elderly people may prefer to delay surgery and manage the pain and the limited mobility rather than undergo a surgery with risks of complications [39]. This may be similar for patients with chronic diseases given their higher risks of short-term complications after surgery [10]. Thirdly, patients with chronic diseases may also prioritise the treatment of their chronic diseases rather than starting surgical treatment of their joint problems [40].

There were several study limitations. First, it is important to mention in this context is that we could not adjust for the severity of the chronic diseases because the administrative data could capture the presence of chronic conditions but not their severity. This is especially important for the interpretation of the observed association between of the number of chronic conditions and the severity of the joint problems at the time of surgery. It is likely that we would have found an even stronger association if we had been able to take severity of the chronic conditions into account.

Furthermore, it is likely that there is a 'healthy-surgical patient effect'. This effect may have contributed to an underestimation of the effect of chronic diseases as a consequence of the selection of patients for surgery being influenced by 'unmeasured' or 'unobserved' confounders that are not accounted for. As a result, patients with chronic diseases who had surgery may be less frail and less severe than patients with a similar chronic disease profile in the general population [41]. In addition, due to the lack of a control group (patients with comorbidities who have not had joint replacement surgery) it is not possible to fully account for this selection bias.

Also, our sample of patients represents $71 \%$ of all patients who had a hip or knee replacement in the English NHS between 2009 and 2016. While the response rate to the PROMs survey is high, non-recruitment may have led to confounders being unevenly distributed between different groups of patients and hospitals [42]. This was especially apparent with only $3 \%$ of patients reported to be from a minority ethnic group, although this may be explained in part by the high percentage of missing data (>10\%). To account for this, we adjusted for clustering of outcomes within hospitals and for socioeconomic factors. This adjustment had a minimal impact on the findings.

The negative consequences of the presence of comorbidities before surgery also need to be interpreted in the context of the outcomes after joint replacement surgery. In our previous systematic review of 70 studies looking at 10 outcomes comparing patients with and without patients chronic diseases, we found that chronic diseases predominantly had an impact on the safety e.g. complications) but little impact on the effectiveness (e.g. functional and pain outcomes) after joint replacement surgery [10]. This suggests that patients with chronic diseases do not benefit significantly less from hip and knee replacement surgery.

\section{Conclusions}

In conclusion, patients with chronic diseases undergoing hip or knee replacement surgery reported more severe pain and a poorer functional status immediately before surgery than patients without chronic diseases. These findings suggest that on average patients with chronic diseases have hip or knee replacement later in the course of their joint disease, likely as a result of delays in access to surgery.

\section{Supplementary information}

Supplementary information accompanies this paper at https://doi.org/10. 1186/s12913-020-05464-3.

Additional file 1. Breakdown of OHS and OKS by pain and functional status questions ( $P=$ pain, $F=$ functional status).

\section{Abbreviations \\ HES: Hospital Episode Statistics; ICD-10: International Classification of Diseases, 10th Revision; MID: Minimally Important Difference; NICE: National Institute for Health and Care Excellence; OHS: Oxford Hip Score; OKS: Oxford Knee Score; PROMs: Patient Reported Outcome Measures programme.}

\section{Acknowledgements}

The authors acknowledge NHS Digital for the Patient Reported Outcome Measures data and the Hospital Episode Statistics Inpatient Admissions data linkage.

\section{Authors' contributions}

BP designed the study, conducted the main study, analysis and wrote the manuscript. $\mathrm{AH}$ helped design the study design, analysis and with the drafting of the manuscript. SK helped with the analysis of the manuscript and revised the manuscript. JR helped with helped with the analysis of the manuscript and revised the manuscript. JvM helped design the study design, with the analysis and the drafting of the manuscript. All authors have read and approved the manuscript.

\section{Funding}

This work was supported by the National Institute for Health Research (NIHR) Collaboration for Leadership in Applied Health Research and Care North Thames at Barts Health NHS Trust. The views expressed are those of the authors and not necessarily those of the NHS, the NIHR or the Department of Health and Social Care. The funding body did not have any role in the design of the study and collection, analysis and interpretation of the data and in writing the manuscript.

\section{Availability of data and materials}

The data that support the findings of this study are available from NHS Digital but restrictions apply to the availability of these data, which were used under license for the current study, and so are not publicly available.

\section{Ethics approval and consent to participate}

The study was approved by the Health Research Authority NHS Research Ethics Committee (Reference: 16/WA/0241) as well as the London School of Hygiene \& Tropical Medicine ethics committee (Reference: 11628).

Consent for publication

Participant consent was not obtained due to the de-identified nature of the data. 


\section{Competing interests}

The authors declare they have no competing interest.

\section{Author details}

'Department of Health Services Research \& Policy, London School of Hygiene \& Tropical Medicine, 15-17 Tavistock Place, London WC1H 9SH, UK. ${ }^{2}$ Clinical Effectiveness Unit, The Royal College of Surgeons of England, London, UK. ${ }^{3}$ Consultant Orthopaedic Surgeon, University College London Hospitals NHS Foundation Trust, London, UK. ${ }^{4}$ Centre for Primary Care and Public Health, Queen Mary University of London, London, UK.

\section{Received: 28 October 2019 Accepted: 24 June 2020} Published online: 01 July 2020

\section{References}

1. Ethgen O, Bruyere O, Richy F, Dardennes C, Reginster JY. Health-related quality of life in total hip and total knee arthroplasty. A qualitative and systematic review of the literature. J Bone Joint Surg Am. 2004;86-a(5):963-74.

2. Weaver M. Pain-level rationing of hip and knee surgery due to cash crisis, admits NHS: the Guardian; 2017. Available from: https://www.theguardian. com/society/2017/jan/26/royal-college-surgeons-slam-plans-hip-kneereplacements-ccgs.

3. Jaakkimainen L, Glazier R, Barnsley J, Salkeld E, Lu H, Tu K. Waiting to see the specialist: patient and provider characteristics of wait times from primary to specialty care. BMC Fam Pract. 2014;15:16.

4. Gwynne-Jones D, losua E. Rationing of hip and knee replacement: effect on the severity of patient-reported symptoms and the demand for surgery in Otago. N Z Med J. 2016;129(1432):59-66.

5. CCG NRaB. Revisions to commissioning policy Management of Musculoskeletal Surgery and Therapeutic Interventions 2017. Available from: http://www.redditchandbromsgroveccg.nhs.uk/EasysiteWeb/getresource. axd?AssetID=123362\&type=full\&servicetype=Attachment.

6. CCGS SE. Service Restriction Policy South Essex 2014. Available from: https:// basildonandbrentwoodccg.nhs.uk/about-us/board-meetings-papers/2014archive/june-2014/729-item-04-1 b-service-restriction-policy-for-boardapproval-050614/file.

7. CCG SaWB. Policy of hip/knee replacement surgery 2017. Available from: https://sandwellandwestbhamccg.nhs.uk/treatment-policies.

8. CCG D. Procedures of Limited Clinical Priority Guideline \& Commissioning Policy 2016. Available from: http://www.dudleyccg.nhs.uk/wp-content/ uploads/2017/11/Procedures-of-Limited-Clinical-Priority-Guideline-April-2 016-CD-XX-070-V2.2.pdf.

9. NICE. Osteoarthritis: care and management [CG177] 2014. Available from: https://www.nice.org.uk/Guidance/cg177.

10. Podmore B, Hutchings A, van der Meulen J, Aggarwal A, Konan S. Impact of comorbid conditions on outcomes of hip and knee replacement surgery: a systematic review and meta-analysis. BMJ Open. 2018;8(7):e021784.

11. Podmore B, Hutchings A, Durand MA, Robson J, Konan S, van der Meulen J, et al. Comorbidities and the referral pathway to access joint replacement surgery: an exploratory qualitative study. BMC Health Serv Res. 2018;18(1):754

12. Desmeules F, Dionne CE, Belzile E, Bourbonnais R, Frémont P. Waiting for total knee replacement surgery: factors associated with pain, stiffness, function and quality of life. BMC Musculoskelet Disord. 2009;10:52.

13. Ozcakir S, Raif SL, Sivrioglu K, Kucukcakir N. Relationship between radiological severity and clinical and psychological factors in knee osteoarthritis. Clin Rheumatol. 2011;30(12):1521-6.

14. Weick J, Bawa H, Dirschl DR, Luu HH. Preoperative opioid use is associated with higher readmission and revision rates in Total knee and Total hip Arthroplasty. J Bone Joint Surg Am. 2018;100(14):1171-6.

15. Judge A, Welton NJ, Sandhu J, Ben-Shlomo Y. Equity in access to total joint replacement of the hip and knee in England: cross sectional study. BMJ. 2010;341:c4092.

16. Martin CT, Callaghan JJ, Liu SS, Gao YB, Warth LC, Johnston RC. Disparity in Total joint Arthroplasty patient comorbidities, demographics, and postoperative outcomes based on insurance payer type. J Arthroplasty. 2012;27(10):1761-5.

17. Neuburger J, Hutchings A, Allwood D, Black N, van der Meulen JH. Sociodemographic differences in the severity and duration of disease amongst patients undergoing hip or knee replacement surgery. J Public Health (Oxf). 2012;34(3):421-9.
18. Kiran A, Geary RS, Gurol-Urganci I, Cromwell DA, Bansi-Matharu L, Shakespeare J, et al. Sociodemographic differences in symptom severity and duration among women referred to secondary care for menorrhagia in England and Wales: a cohort study from the National Heavy Menstrual Bleeding Audit. BMJ Open. 2018;8(2):e018444.

19. Digital N. Patient reported outcome measures (PROMs) 2017. Available from: http://content.digital.nhs.uk/proms.

20. Patient Reported Outcome Measures. 2017. Available from: https://digital. nhs.uk/data-and-information/data-tools-and-services/data-services/patientreported-outcome-measures-proms.

21. Bayliss EA, Ellis JL, Steiner JF. Subjective assessments of comorbidity correlate with quality of life health outcomes: initial validation of a comorbidity assessment instrument. Health Qual Life Outcomes. 2005;3:51.

22. Bream E, Charman SC, Clift B, Murray D, Black N. Relationship between patients' and clinicians' assessments of health status before and after knee arthroplasty. Qual Saf Health Care. 2010;19(6):e6.

23. Wylde V, Learmonth ID, Cavendish VJ. The Oxford hip score: the patient's perspective. Health Qual Life Outcomes. 2005;3(1):66.

24. Ostendorf M, van Stel HF, Buskens E, Schrijvers AJ, Marting LN, Verbout AJ, et al. Patient-reported outcome in total hip replacement. A comparison of five instruments of health status. J Bone Joint Surg Br. 2004;86(6):801-8.

25. Baker PN, van der Meulen JH, Lewsey J, Gregg PJ. The role of pain and function in determining patient satisfaction after total knee replacement. Data from the National Joint Registry for England and Wales. J Bone Joint Surg Br. 2007:89(7):893-900.

26. Government DCL. The English index of multiple deprivation (IMD) 2015- guidance. London: Ministry of Housing, Communities \& Local Government; 2015.

27. White IR, Royston P, Wood AM. Multiple imputation using chained equations: Issues and guidance for practice. Stat Med. 2011;30:377-99.

28. Beard DJ, Harris K, Dawson J, Doll H, Murray DW, Carr AJ, et al. Meaningful changes for the Oxford hip and knee scores after joint replacement surgery. J Clin Epidemiol. 2015;68(1):73-9.

29. Dunn KM, Croft PR. The importance of symptom duration in determining prognosis. Pain. 2006;121(1-2):126-32.

30. Lau YS, Harrison M, Sutton M. (Association Between Symptom Duration and Patient Reported Outcomes Before and After Hip Replacement Surgery). Arthritis Care Res. 2020;72:423-31.

31. Suarez-Almazor ME, Souchek J, Kelly PA, O'Malley K, Byrne M, Richardson M, et al. Ethnic variation in knee replacement - patient preferences or uninformed disparity? Arch Intern Med. 2005;165(10):1117-24.

32. Cobos R, Latorre A, Aizpuru F, Guenaga JI, Sarasqueta C, Escobar A, et al. Variability of indication criteria in knee and hip replacement: an observational study. BMC Musculoskelet Disord. 2010;11:249.

33. Cross WW, Saleh KJ, Wilt TJ, Kane RL. Agreement about indications for total knee arthroplasty. Clin Orthop Relat Res. 2006;446:34-9.

34. Dieppe P, Basler HD, Chard J, Croft P, Dixon J, Hurley M, et al. Knee replacement surgery for osteoarthritis: effectiveness, practice variations, indications and possible determinants of utilization. Rheumatology. 1999;38(1):73-83.

35. Mancuso CA, Ranawat CS, Esdaile JM, Johanson NA, Charlson ME. Indications for total hip and total knee arthroplasties - results of orthopaedic surveys. J Arthroplast. 1996;11(1):34-46.

36. Cronström A, Nero H, Dahlberg LE. Factors associated with patients' willingness to consider joint surgery after completion of a Digital osteoarthritis treatment program: a prospective cohort study. Arthritis Care Res. 2019;71(9):1194-201.

37. Walker J, Halbesma N, Lone N, McAllister D, Weir CJ, Wild SH. Socioeconomic status, comorbidity and mortality in patients with type 2 diabetes mellitus in Scotland 2004-2011: a cohort study. J Epidemiol Community Health. 2016;70(6):596-601.

38. Delpierre C, Lauwers-Cances V, Datta GD, Lang T, Berkman L. Using selfrated health for analysing social inequalities in health: a risk for underestimating the gap between socioeconomic groups? J Epidemiol Community Health. 2009;63(6):426-32.

39. Hudak PL, Clark JP, Hawker GA, Coyte PC, Mahomed NN, Kreder HJ, et al. "You're perfect for the procedure! Why don't you want it?" elderly arthritis patients' unwillingness to consider total joint arthroplasty surgery: a qualitative study. Med Decis Mak. 2002;22(3):272-8.

40. Pugh JA. Priority setting for patients with multiple comorbidities: diabetes may not end up number one. J Gen Intern Med. 2007;22(12):1783-4.

41. Dreinhofer KE, Dieppe P, Sturmer T, Grober-Gratz D, Floren M, Gunther KP, et al. Indications for total hip replacement: comparison of assessments of 
orthopaedic surgeons and referring physicians. Ann Rheum Dis. 2006;65(10): 1346-50.

42. Hutchings A, Neuburger J, van der Meulen J, Black N. Estimating recruitment rates for routine use of patient reported outcome measures and the impact on provider comparisons. BMC Health Serv Res. 2014;14(1):66.

\section{Publisher's Note}

Springer Nature remains neutral with regard to jurisdictional claims in published maps and institutional affiliations.

Ready to submit your research? Choose BMC and benefit from:

- fast, convenient online submission

- thorough peer review by experienced researchers in your field

- rapid publication on acceptance

- support for research data, including large and complex data types

- gold Open Access which fosters wider collaboration and increased citations

- maximum visibility for your research: over $100 \mathrm{M}$ website views per year

At BMC, research is always in progress.

Learn more biomedcentral.com/submissions 